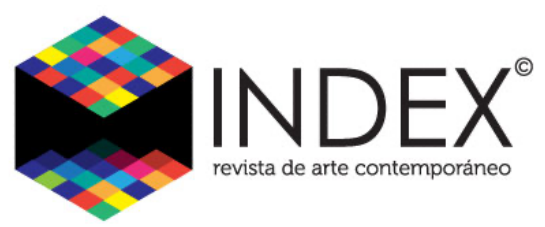

No. 11. MAY 2021.

ISSN: 2477-9199

\author{
Temas del arte
}

DOI: $10.26807 /$ cav.vi11.425

\title{
LA IMAGEN BARROCA COMO ESTRATEGIA DE SUJECIÓN DEL INDÍGENA AL PODER CIVIL Y ECLESIÁSTICO EN QUITO DE LA SEGUNDA MITAD DEL SIGLO XVII. EL CASO DE LA OBRA CURACIÓN DE UNA INDIA ENDEMONIADA
}

\section{THE BAROQUE IMAGE AS A STRATEGY OF SUBJECTION OF THE INDIGENOUS TO THE CIVIL AND ECCLESIASTICAL POWER IN QUITO IN THE SECOND HALF OF THE SEVENTEENTH CENTURY. THE CASE OF THE PAINTING HEALING OF $A$ DEMONIZED INDIAN}

Oscar Enriquez Capa

\section{Resumen}

En este artículo se estudia la pintura titulada Curación de una india endemoniada ... (1697-1706) de Miguel de Santiago en el contexto de la evangelización indígena en la segunda mitad del siglo XVII. Esta imagen, ubicada en la iglesia de Guápulo como parte de la serie "milagros de la virgen" ofrece la posibilidad de exponer dos sentidos que anidan en su propósito devocional. Por un lado, el cuadro condensa el imaginario sobre la extirpación de la idolatría indígena en los Andes al formar parte de un conjunto de recursos destinados para su adoctrinamiento y, por otro, la forma en que las elites imaginaban la estructura socio política en Quito que se concretaría mediante la implantación de un gobierno civil y moral. A partir de esta doble entrada se propone observar que esta representación, aunque surgió del amplio proyecto contrarreformista en América, respondía a la expresión local de una sociedad que intenta constituir su propia forma de poder. Para ello, se contextualiza la obra, luego se analiza su lenguaje pictórico y finalmente, se extrae algunas inferencias sobre la función de la imagen en el espacio litúrgico. 
Palabras clave : Barroco, culto mariano, arte religioso, evangelización indígena

\begin{abstract}
This article analyzes the painting titled Healing of a demonized Indian ... (1697-1706) by Miguel de Santiago in the context of indigenous evangelization in the second half of the 17th century. This image placed in Guápulo church, as part of the series "Miracles of the virgin", expose two senses of a devotional purpose. On one hand, the painting condenses the imaginary about the removal of indigenous idolatry in the Andes as part of a set of resources destined for its indoctrination; and, on the other hand, the way in which the elites imagined the socio-political structure in Quito that would be possible placing a civil and moral government. With this double entry it can be observed that this image, although arose from the broad counter-reformist project in America, responded to the local expression of a society trying to constitute its own power. I will place a context for this artwork, then analyze the pictorial language, and finally, establish some conclusions about the function of the image in the liturgical space.
\end{abstract}

Keywords: Baroque, Marian cult, religious art, indigenous evangelization

\title{
Biografía del Autor
}

Oscar Enríquez Capa (Quito, 1978). Máster en Ciencias Políticas FLACSO, Máster (c) en Historia, UASB y Licenciado en Artes Plásticas, UCE.

\section{Introducción}

El cuadro conocido como Curación de una india endemoniada era parte de la serie Milagros de la Virgen realizada para la iglesia de Guápulo de Quito. La pintura al óleo sobre tela entraría en la fase culminante que cerraría el largo proceso de construcción de la Iglesia de Guápulo. El periodo de medio siglo comprendido entre 1646, fecha que aparece en la leyenda de la imagen y 1706 , fecha última de la probable realización del cuadro, corresponden a una fase de apogeo del poder local en Quito (Coronel, 2008; Salgado, 1997). Este poder encuentra medios institucionales para sujetar a la población a una estructura de gobierno civil y moral, asidos a la estructura eclesial (Pérez, 2015). Asimismo, este periodo coincide con el declive de las extirpaciones de idolatría indígena en el espacio andino, desde su fase institucionalizada que empezó en 1607 con los procesos iniciados en Huarochirí por los jesuitas Francisco de Ávila, Fernando de Avendaño y Joseph de Arriaga (Cordero, 2016).

En el contexto de la Audiencia de Quito del periodo al que nos referimos, se ha investigado esporádicamente sobre la extirpación de idolatrías, asimismo, existen pocas fuentes que constaten este hecho, frente a la abrumadora cantidad de casos y fuentes que se han estudiado en el contexto andino. 
El obispo de Quito Alonso de la Peńa Montenegro que ejerció entre 1653 y 1687, decía en su Itinerario para párrocos de indios que "no había cosa notable en cuestión de idolatrías por la actitud sosegada de los Indios” (1771). ${ }^{1}$ No obstante, los estudios sobre la evangelización indígena hasta la actualidad exponen de modo más o menos general que había una expectativa pesimista sobre los resultados del proceso extirpador. Esto se hace evidente en la cantidad de informes, cartas, tratados, etc., que indican la recurrencia a sus antiguas prácticas paganas como principal obstáculo para la plena conversión de los indígenas al cristianismo. A su vez, este retorno de los naturales a su pasado infiel era explicado tanto en la herencia cultural como en la sanguínea (Peña Montenegro, 1771).

En este contexto, aún faltan explicaciones sobre si este declive de la empresa extirpadora de la idolatría indígena guarda relación con la emergencia y posterior apogeo de estos poderes locales. El análisis que se presenta intentará abrir preguntas sobre esta relación, desde algunos aportes de la historia cultural y la historia de la visualidad. Primero, existía una sociedad que se disputaba los espacios de poder y las elites se imaginan una estructura que bien podría estar representada en el cuadro de nuestro análisis. Segundo, aunque no se puede asegurar una mentalidad criolla, sino un siglo después existía una pretensión de constituir una estructura en la que la memoria indígena era puesta como una nota al margen de la historia europea. Entonces, ¿̨era una imagen con un doble sentido para las "dos repúblicas" la de indios y la de españoles? Es decir, el mensaje que negaba las prácticas idolátricas a los indígenas y el mensaje que reafirmaba el imaginario de esta república cristiana ¿podrían expresarse en el cuadro?

Aunque una representación no es una imagen especular de la sociedad que la produce, creemos que es un punto de partida imprescindible para comprender ciertos aspectos de la organización estamental y las relaciones asimétricas en la configuración social, dada su estructura y los elementos que condensa. Esta imagen ha sido citada en estudios sobre la biografía o la obra de Miguel de Santiago. Asimismo, ha sido referenciado en algunos estudios sobre la evangelización indígena. Sin embargo, no ha recibido una atención directa que indague en su lenguaje pictórico su carácter semántico y su función dentro del contexto de la llamada "conquista espiritual"2 o "extirpación de idolatrías". En ese sentido, la estrategia de análisis consiste en exponer sus elementos visuales, sus políticas de representación en relación con el proceso extirpador y la construcción de "fronteras étnicas" (Salgado 1997).

\section{Evangelización indígena y los recursos pedagógicos de la imagen}

El proceso conocido como extirpación de idolatrías se extendió de manera desigual en los Andes, siendo la Audiencia de Quito una de las "provincias" del virreinato de Lima con menos casos. Tal es así, que las visitas de idolatrías, institución que se encargó de tratar estos asuntos, se concentró en sectores rurales, principalmente, cercanas a Lima. Como se mencionó, fue a inicios del siglo XVII que se impulsó la primera ola extirpadora que adquirió un esquema sistematizado. Toda esta experiencia de

\footnotetext{
${ }^{1}$ El texto titulado "Itinerario para párrocos de Indios. En que se tratan las materias más particulares tocantes a ellos para su buena administración", fue publicado en 1668.

${ }^{2}$ Concepto que debate Hans Jürgen Prien sobre su conveniencia actual, frente a los relatos que desarrollaron los evangelizadores y tratadistas, por un lado; y por otro, los historiadores tradicionales desde el siglo XIX hasta mediados del siglo XX.
} 
adoctrinamiento tenía como núcleo los postulados de la contrarreforma emanados a partir del Concilio de Trento (1545-1563). A su vez, estos principios fueron aclimatados al contexto americano y andino por los Concilios Limenses II (1567-8) y III (1582-83) y los Sínodos de Quito II (1594) y Loja III (1596).

El sustrato teológico provisto por sus postulados, intentaban unificar criterios frente a los debates y confrontación que podría existir dentro del clero y frente al gobierno civil y militar. Un criterio fundamental para la evangelización indígena, que emanó de este estos procesos, fue la territorialización de la doctrina en donde los párrocos doctrineros educarían a los naturales (Peña Montenegro, 1771). Para este propósito se crearon las "reducciones de indios", unidades mínimas de administración de la población que permitían el orden y el control. Posteriormente, estos espacios territoriales se conocerían como doctrinas o "parroquias de indios", generalmente rurales; la mayoría vinculadas a centros de producción (Glave, 2017).

Así, para la segunda mitad del siglo XVII se podría observar un tejido territorial importante. Como menciona Jorge Moreno Egas (1991), a partir del análisis del estado de las doctrinas, solo en "las cinco leguas de Quito” se encontrarían 29 doctrinas con su respectivo doctrinero (secular o regular) y sus feligreses indígenas que variarían entre 200 y 800 . Esto indicaría una estructura eclesial con bastante penetración e influencia en las sociedades andinas. Pese a ello, las diferencias culturales no dejaban de ser un obstáculo importante para el propósito que legitimaba el papel de los evangelizadores en América.

La efectividad de la "conquista espiritual" necesitaría otro espacio y enfoques de análisis, que, sin duda, involucrarían la evolución de toda la empresa evangelizadora. Aquí, únicamente nos referimos a un periodo acotado y a unos elementos concretos de la labor doctrinal durante el periodo de larga duración que enmarca la historia de la evangelización indígena. Sin embargo, cabe preguntarse si todo ese despliegue de políticas, estrategias y proyectos, contrastado con buena cantidad de documentos confirmarían cierto pesimismo sobre la evangelización indígena, y, además, de que sus resultados tendían a ser negativos.

Como se observa del esquema presentado, hay un contexto atravesado por la evangelización indígena como principal dinamizador del papel del clero en los Andes. Creemos que el cuadro "Curación de una india endemoniada" abre una puerta importante para indagar su función dentro de su espacio para la liturgia en el que no se conjugan elementos únicamente religiosos, sino también sociales y culturales. El siglo XVII quiteńo se ha caracterizado por sus innumerables crisis particularmente económicas. Muchas de ellas atribuidas a varias erupciones volcánicas. Estas catástrofes naturales habrían empujado a la sociedad quiteńa a sujetarse a las devociones cristianas, particularmente el culto mariano, incluso sobre los santos. Esto, sin embargo, ocurría en los espacios controlados por la religión oficial.

Por el contrario, en las doctrinas de indios, generalmente rurales, donde un solo párroco tenía a su haber, la educación y adoctrinamiento de cientos de feligreses se hacía mucho más difícil el control

\footnotetext{
${ }^{3}$ Eran extensos debates que pensaban las formas de mediar la evangelización indígena, la consecución, observación y promoción del clero, y su rol en la configuración del territorio.
} 
moral. Este era un escenario propicio para que los indígenas revivan las antiguas devociones paganas que se mantenían latentes. Como afirmaba el obispo de la Peńa los naturales regresaban a sus prácticas idolátricas porque aún recibía novedad de hechicerías, supersticiones y brujerías que sus párrocos le contaban de su ejercicio pastoral cotidiano (Peña Montenegro, 1771). Por otro lado, también existían reclamos que se hacía a los obispos, desde visitadores o autoridades civiles, por el "estado lamentable" de conocimiento de los "rudimentos" del evangelio que había en los naturales.

Avia pocos dias que

vinieron a esta Ciudad unos indios

que se llaman los colorados que caen

hacia el mar del sur terminos de

los sicchos, que no distan de esta Ciu-

dad quarenta leguas, y de escaso yo

de saber en que punto y estado teniuan

la sagrada balanza del evangelio, con

dos interpretes les hize examinar, y que

dexavan las oraciones, y el mas ladino

de ellos, que dixo era el cazique, solo

supo la mitad del Padre nuestro en

nuestra lengua Española, y porque pre-

sumi que solo lo pronunciaba como un

papagayo, adverti a los interpretes que

Le dixera lo volviese en su lengua

materna, y llanamente confeso que no 
sabia, con que confirma mi sospecha

y por certificarme mas, le hize pregun-

tar que si avia otros, y quien era y

quantos dioses avia, y lo que respondio

a esto ultimo fue alczar quatro dedos

en señal de que avia quatro dioses y

luego dixo que dos, con que se me con-

movieron las entrañas, viendo que tan

cerca de nosotros aia tanto barbarismo

y que los obispos, sucesores de los santos

Apostoles estiendan tan poco su vos que

aun no alcanse a partes tan vezinas (AGI, Quito, 13, R. 11, N.34, 1660.) ${ }^{4}$

La voz del visitador no se puede extender a toda la feligresía ni a todas las doctrinas de indios, sin embargo, nos permite imaginar la justificación que se elaboraba desde el clero para solventar la diferencia cultural con otras estrategias comunicativas. No obstante, cabe indicar que gran parte de los registros, cartas informes y documentos, así como los tratados y manuales, desconocen los procesos de apropiación de los elementos del cristianismo por parte de los indígenas. Es preciso preguntarse si esta diferencia cultural y los resultados negativos que supuestamente habrían tenido después de siglo y medio de evangelización explicarían parcialmente la profusión de imágenes devocionales.

Aunque se ha mencionado que el uso de imágenes fue impulsado por los propósitos de la contrarreforma, la aclimatación de estas políticas en los Andes respondería a una expresa intención pedagógica para enfrentar las diferencias culturales. En todo caso, la imagen de la virgen María se erige como uno de los elementos fundamentales para la difusión de la doctrina cristiana. Tal parece que uno de los recursos del culto mariano tiene que ver con la confluencia de un sentido universalista del

\footnotetext{
${ }^{4}$ Fragmento de una carta enviada al Rey Felipe IV por Andrés Rocha, que mediante visita general, constata
} el estado de las doctrinas y eleva su reclamo contra el obispo Alonso de la Peña Montenegro. 
mensaje cristiano y a la vez un carácter localista, porque permitía a los feligreses la incorporación de elementos locales, lo que derivaba en una incipiente apropiación e identificación regional del culto. De esta manera, la dicotomía universal-local aparece como un potente dinamizador del mensaje cristiano que permitía ciertas "libertades" en cuanto a las características que cada localidad le atribuía a la virgen (o los santos) como mediadora entre las cosas del orden natural, preternatural y sobrenatural (Hidalgo, 2011).

\section{La "india endemoniada” y la virgen de Guápulo}

En la Iglesia de Guápulo, como comúnmente se le conoce a este templo de Quito, se encuentra el cuadro atribuido a Miguel de Santiago que concita nuestras reflexiones (figura 1). La realización de la pintura se ha fechado tentativamente entre 1699 y 1706. El cuadro tiene la siguiente inscripción: "En el año de 1646 en presencia del Señor Obispo Don Agustín Duarte y el presidente Don Martín de Arriola, llegó una india endemoniada estando en la misa mayor y quedó muerta y después que acabó la misa se levantó sana y buena, visto [obispo?] agarro de la frente preguntando para qué la agarraba hacia esta buena i sana” (Estebaranz, 2013, p. 231).

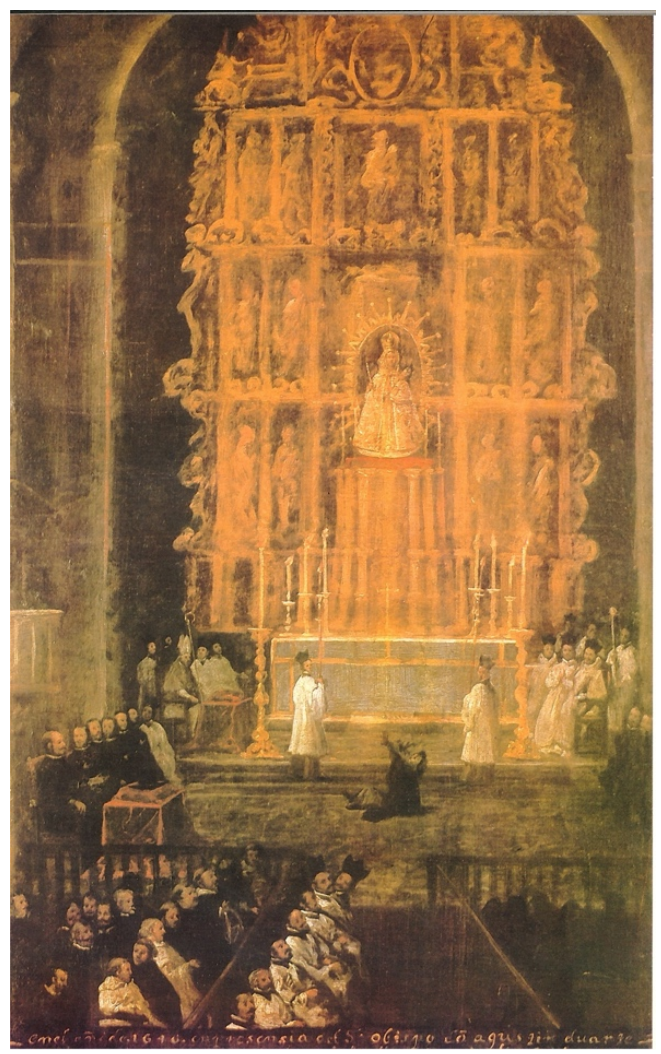

Figura 1. Curación de una india endemoniada, Miguel de Santiago, 1699-1706

Fuente: Enciclopedia Salvat (1977, p.159.) 
Debido a la calidad y características de los cuadros se especula que hubo una intervención de sus colaboradores. No obstante, por el tratamiento, y composición de la jerarquía eclesiástica creemos, con mucha probabilidad, que el cuadro en cuestión se trata de un trabajo de Miguel de Santiago. La serie, compuesta por doce cuadros que habría sido "encargada por la población local, a través de la cofradía de la Virgen de Guápulo, correspondiendo a las primeras imágenes pictóricas de milagros ocurridos en territorio quiteño [tal fue su importancia devocional que] en 1644 se proclamó a la Virgen de Guápulo Patona de Armas reales, por Real Cédula de Felipe IV" (Estebaranz, 2013, p. 228).

Así, la pintura tiene el claro propósito de apoyar la evangelización mediante la exposición de milagros concretos (Vargas, 1970). Aunque la imagen era un recurso didáctico, también muestra la cotidianidad del rito católico y la estructura eclesial. "aunque se puede interpretar como anécdotas algunos detalles de las pinturas, la mayoría de estas se centra en la importancia de la Virgen de Guápulo como obradora de milagros" (Estebaranz, 2013, p. 225). En este sentido, todo indicaría que la serie está realizada sobre relatos reales que circulaban en Quito sobre los milagros de la Virgen.

Asimismo, cabe indicar que es la única imagen de la serie que se refiere al interior del templo porque el resto corresponden a paisajes del entorno quiteńo realizados desde Guápulo. Por ello, algunos autores desde el siglo XIX le habrían considerado como el "pionero del paisajismo en Ecuador" con un claro sesgo nacionalista. No obstante, de la importancia del paisaje en su narrativa, el tropo principal es la virgen. Ahora bien, queremos enfatizar que, en estos paisajes, la virgen aparece como un ente sobrenatural, por el contrario, en "Curación de una india endemoniada" la virgen aparece en su estado natural, cobijando el retablo del altar mayor de la iglesia de Guápulo.

La imagen representa el interior de la Iglesia de Guápulo y está dominada por un intenso dorado que contrasta con un fondo oscuro, recurso habitual en el barroco. Desde una vista elevada muestra el retablo y altar enmarcados por las columnas que sostienen la bóveda y que muestra como principal personaje a la Virgen de Guadalupe, ${ }^{5}$ que cobija la escena. Desde un corte transversal, la virgen se encuentra casi centrada en el tercio superior, configurando una composición triangular. Respecto de todo el formato, la virgen se encuentra en la línea de horizonte, es decir el espectador comparte la altura de visión de la virgen. Irradia luminosidad gracias a los tonos siena y dorado y el contraste con los tonos oscuros del tercio inferior y los bordes del retablo. En el tercio central se desarrolla la escena principal que es enmarcada por los sacristanes. En los tercios intermedio e inferior, se encuentra la feligresía organizada según las jerarquías, prestando atención al espectáculo que se presenta en la parte baja y central en el que se dibuja un personaje apenas reconocible: la imagen de la "india endemoniada" en negro.

Por su disposición, dentro del espacio arquitectónico de la planta de la Iglesia como también de las vestimentas se puede deducir las relaciones jerárquicas y establecer los mandos clericales, así como también civiles. Aunque solo se definen efectivamente a las autoridades y figuras más importantes, los feligreses de jerarquías más bajas tienen formas determinadas y es aquí precisamente donde queremos centrar la atención. La feligresía, menos importante que las autoridades, constituye un elemento

\footnotetext{
${ }^{5}$ Representación original de la Virgen de Guadalupe tallada por Diego de Robles y policromada por Luis Rivera en el siglo XVI. Lamentablemente se quemó en un incendio en 1839.
} 
pictórico marginal dentro de la composición, que, sin embargo, presentan cualidades humanas reconocibles. En el sentido en que Carlo Ginzburg expone como opera el "método indiciario" esta forma de pintar constituiría un gesto espontáneo y natural (2013). En ese sentido, dentro de la factura de un cuadro, es una forma intuitiva y menos consciente de lanzar trazos dentro de la práctica pictórica $y$, sin embargo, son reconocibles las formas humanas determinadas.

En contraste, la representación de la india endemoniada solo es identificable por el contexto narrativo, es decir, que si se extrae el dibujo de dicho contexto perdería todo sentido y sería totalmente irreconocible. Esto porque la representación de la india endemoniada es una síntesis tanto gestual como cromática, en la cual, mediante la descripción previa apenas son reconocibles los brazos y el rostro, con dos minúsculas manchas oscuras que posiblemente refieran a los ojos. ¿Es esta una síntesis producida por el gesto intuitivo del artista, como en el caso de la feligresía de menor rango? o, ¿es una construcción consciente de la antítesis de la Virgen? Creemos que, por el propósito que tenía el personaje en contraste con el de la Virgen y su ubicación tanto en el plano pictórico y narrativo, después, el trazo y definición, es probable un propósito consciente de construir un sujeto homogéneo, monolítico. Un sujeto invariable en el tiempo y extensible a todo el Nuevo Mundo; un "indio retórico" que se lo encuentra en la en la textualidad y no en una realidad aprehendida (Borja, 2002). Además, el contraste, no era solo en el mensaje que se intentaba dar, respecto de la jerarquía de las dos figuras femeninas, hay una oposición radical, entre la belleza y luminosidad de la Virgen frente a la fealdad y oscuridad de la representación de la "india endemoniada" pese a que ya era curada por la obra milagrosa de la Virgen. Así, una india endemoniada caracterizada por la fealdad y por carecer de forma es curada de sus males por intermediación de una virgen luminosa y bella.

Cabe añadir que la serie de los Milagros de la Virgen, de la que forma parte el cuadro descrito, corresponde al subgénero de las imágenes doctrinales, donde las "narraciones directas que representan los eventos principales de la historia de la imagen [...] toman lugar en un paisaje andino específico" (Rappaport y Cummins, 2016, p. 239). Una narración donde se impone lo sobrenatural por encima de lo preternatural (Hidalgo 2011). El lugar de devoción y peregrinaje desde al menos, la segunda mitad del siglo XVI. Con importante presencia indígena, era un templo que se ubicaba en la frontera de la ciudad con el propósito de pacificarla mediante la implantación del culto mariano para que se sobrepongan a deidades más o menos correspondientes, e integrando elementos y suprimiendo ídolos de su profusa idolatría (Ramón, 2008). Posteriormente en el siglo XVII ya se había ganado un prestigio por las conversiones, es decir, su victoria sobre la idolatría (Terán, 1994). "Uno de los objetivos inmediatos de la alfabetización visual al largo de América era imprimir sobre los espectadores indígenas la noción de que algunas imágenes (las imágenes católicas) eran imágenes verdaderas, mientras otras imágenes (imágenes nativas) eran falsas y, a su vez, que algunos espacios eran sagrados mientras otros eran demoniacos" (Rappaport y Cummins, 2016 p. 172).

Por otro lado, la virtud o milagros narrados debían ser leídos en una geografía específica y ciertamente, la representación remite a un templo específico y el detalle de su interior. No obstante, por la geografía de la ciudad era un lugar de peregrinaje y el lugar de paso hacia la región oriental. Pero es llamativa la localización de la Iglesia de Guápulo en la urbe quiteńa. Principalmente porque las imágenes, según Gruzinski, promovían la integración, mediante la territorialización del culto, más allá 
de la evangelización efectiva. Salgado (1997), afirma que se encuentra en un espacio donde se marcaba la frontera entre la civilización y la barbarie, un espacio particularmente propicio para borrar la memoria indígena y construir una frontera étnica. Esfuerzo y empeño de los evangelizadores si se considera que los procesos previos dieron demasiada permisividad.

\section{Reflexiones finales}

La representación que realiza Miguel de Santiago sobre el milagro que obra la Virgen de Guadalupe (Guápulo) sobre la "india endemoniada” condensa toda la experiencia que había obtenido de sus trabajos previos, particularmente, en el convento de San Agustín. Aquí, había dedicado gran parte de sus de composiciones a la jerarquía eclesiástica que se cuentan por decenas. A Santiago le precedía una reputación que le codeaba con las cofradías, personas ligadas a las élites, gobierno civil y principalmente eclesiástico. De ahí podemos inferir que entiende los estamentos y jerarquías clericales, conoce su estructura, su importancia y significado en el contexto social.

Por otro lado, la interpretación que Santiago hace de los milagros también está embebido de un conocimiento cabal de la doctrina, los misterios y dones; que también se colige de su relación constante con miembros del clero durante el trabajo de toda su vida artística. Es decir, podemos inferir que Santiago es consciente de lo que quería representar y el mensaje que quería transmitir, dada su experiencia y experticia. Entonces ¿qué es lo que nos quiere decir, más allá del mensaje doctrinal y propósito pedagógico? ¿Tenía clara la imposición de una cultura que se estaba "criollizando" sobre la cultura andina, que, a su vez, concretaba una nueva experiencia desde el contacto y relación asimétrica con los españoles?

Los esfuerzos por traducir instrumentos pastorales, organizar en policía, enseñar con la implementación de las imágenes habla de la recursividad de los evangelizadores. Pero también, de la brecha que existía entre gran parte de las culturas nativas y europeas, ambas en constante transición por su contacto en los templos cristianos, estos espacios sociales que eran nuevos de comunión. Otro de los aspectos que abre este análisis remite al carácter multisemántico de las imágenes. Esta cualidad se multiplica en los procesos de adoctrinamiento al evidenciar la diferencia cultural y las formas de apropiación de las imágenes y en general de los recursos pedagógicos que utilizaban los evangelizadores. La audacia del indio ladino que no atina a decir el padre nuestro, pero especula con la cantidad de dioses y la imposibilidad consciente o inconsciente de representar a la india endemoniada visibilizan lo dinámico que habría sido la comunicación entre evangelizadores y feligreses.

Tal vez, la representación de la "india endemoniada" deja entrever el esfuerzo de parte de los evangelizadores por imaginar un orden social y político que aún estaba por establecerse y que veían con ahínco quienes se adherían a ese proyecto. Pero, hilando más fino, probablemente la representación muestra un sujeto indígena que, construido desde la visión cristiana y europea se esforzaba por "reducir"

y "civilizar" más que comprenderlo, porque era un sujeto peligroso para el gobierno civil y moral que se implantaba localmente. En otras palabras, si ese esfuerzo civilizatorio y evangelizador intentaba borrar la memoria indígena a partir de su homogeneización, la imagen de la india endemoniada sería un breve 
indicio que nos permitiría imaginar una historia aborigen velada en la cual se le negaba al indígena la posibilidad de optar por su propio destino como sujeto político en el nuevo proyecto criollo.

\section{Bibliografía}

AGI, Quito, 13, R. 11, N.34, 1660

Borja, J., 2002. Los indios medievales de fray Pedro de Aguado. Construcción del idólatra y escritura de la historia en una crónica del siglo XVI. Bogotá.

Bernand C. y Gruzinski S., 1992. De la idolatría. Una arqueología de las ciencias religiosas. México, Ed: Fondo de Cultura Económica.

Cordero Valarezo, M., Institucionalizar y desarraigar, Las visitas de idolatrías en la Diócesis de Lima, siglo XVII. Lima: Instituto Riva Agüero. Perú, 2016.

Coronel, V., 2008. Pensamiento político jesuita y el problema de la diferencia colonial. En: Radiografía de la Piedra. Los Jesuitas y su templo en Quito. Jorge Moreno Egas ... [et al.].Quito: FONSAL.

Estebaranz, A., 2013. El paisaje: los Milagros de la Virgen de Guápulo. En: El pintor quiteño Miguel de Santiago (1633-1706).

Ginzburg, C., 1999. “Indicios. Raíces de una paradigma de inferencias indiciales”. En: Mitos emblemas indicios. Morfología e historia. 2da reimp., Barcelona: Editorial Gedisa, S.A. pp. 138-175.

Glave, L., 2017. La cuadratura del círculo y las rendijas del encierro: política de reducción de indios en los Andes en tiempos del virrey Toledo. En: reducciones. La concentración forzada de las poblaciones indígenas en el Virreinato del Perú. Akira Saito y Claudia Rosas Lauro, editores. Lima, Fondo Editorial PUCP. Pp. 103-146. 
Gruzinski, S., 1994. Los efectos admirables de la Imagen barroca. En: La guerra de las imágenes. De Cristóbal Colón a Blade Runner (1492-2019), México, Editorial Fondo de Cultura Económica.

Hidalgo Lehuedé, J., 2011. "Redes Eclesiásticas, procesos de extirpación de idolatrías y cultos andinos colonials en Atacama. Siglos XVII y XVIII". Estudios Atacameños. No. 42. (Instituto de Investigaciones Arqueológicas y Museo, Universidad Católica del Norte), pp.113-152. URL: http://www.jstor.org/stable/41825378

Moreno Egas, J., 1991. Las Doctrinas de la Audiencia de Quito en los siglos XVI y XVII, revista del Instituto de Historia Eclesiástica Ecuatoriana, Quito.

Peña Montenegro, A. de la, 1771. Tratado Quarto, de la idolatría. En: Itinerario Para Párrocos de Indios. En que se tratan las materias mas particulares tocantes a ellos para su buena Administración (1985)[1771] (Publicación original en 1668), Quito: Editorial Corporación de Estudios y Publicaciones, pp.170-183.

Pérez, P., 2015. Sujetos a Dios y rey. El poder pastoral en el virreinato del Perú. 1650-1700 Tesis doctoral. Facultad Latinoamericana de Ciencias Sociales, Sede, Ecuador.

Prien, H., 2000. "La conquista espiritual”, Manuel Burga, edit., Historia de América Andina, Vol.2, Formación y apogeo del sistema colonial, 355-399. Quito: Universidad Andina Simón Bolívar/Libresa.

Ramón, G., 2008. La nueva historia de Loja. La historia aborigen y colonial. Loja: Gráficas Iberia.

Rappaport, J. y Cummins T., 2016. Más allá de la ciudad letrada: letramientos indigenas en los Andes. Mercedes López Rodríguez. (trad.) Bogotá: Editorial Universidad del Rosario.

Salgado, M., 1997. La imagen de María, la historia en una imagen. Tesis de Maestría en Historia Andina. Tesis de Maestría. Quito. FLACSO. 
Terán Najas, R., 1994. “Arte espacio y religiosidad en el Convento de Santo Domingo”. Serie Estudios y Metodologías de preservación del patrimonio cultural. No 4 Quito: Ediciones Libri Mundi.

Vargas, J., O.P., (Coord.) 1997. Historia del Arte ecuatoriano. Tomo 2 Quito: Salvat Editores Ecuatoriana, S.A.

Enviado: 2021-03-18

Aceptado: 2021-05-03 